\title{
31
}

\section{Quality Achievement: Current Practices and The Way Ahead}

\author{
J. Barrie Thompson
}

School of Computing and Information Systems, University of Sunderland, Priestman Building, Sunderland, SR1 3SD, United Kingdom

\begin{abstract}
The efficient production of quality software is a major goal for many organisations and the use of systematic methods, automated tools and quality assurance procedures can all assist in reaching this goal. Results from various surveys and research investigations relating to the acceptance or otherwise of these practices are reported. The major reasons for slow adoption of the practices are given and the problems which are currently restraining progress are identified, in particular those relating to personnel. Proposals are presented concerning the actions which should be taken regarding professionalism, education and technology transfer for there to be a significant improvement in the achievement of quality.
\end{abstract}

Keyword Codes: D.0, D.2.0, K.7.0

Keywords: Software, Software Engineering, Professionalism

\section{INTRODUCTION}

A recurring theme within software development has been the problem of poor quality software. This problem has underpinned a 'software crisis' which has lasted since the nineteen sixties and which led to the term Software Engineering (SE) being introduced in 1968 [1]. The concept of SE was originally intended to provide a provocative theme at the conference, but it has evolved over the last 25 years into a technological discipline of considerable importance especially within academic institutions. However, in the call for papers for this conference it was recognised that:

"As the world becomes increasingly dependent on the use of computers, the need for quality software which can be produced at reasonable cost increases. Yet the goal of improving software quality and productivity remains an elusive one. This is so in almost all application areas including business oriented applications. Software development is not yet an engineering practice."

There are many and various reasons why, outside academic institutions, software development has failed to be recognised as an engineering practice and why there has been across industry in general and the commercial sector in particular a failure to adopt SE practices. In the following sections of this paper I will outline what many of the major reasons are and I will suggest how we should approach the future if we are to substantially improve the current situation. Firstly, the results from surveys and research investigations, which my research group have undertaken, and which relate to the acceptance of these SE developments in the UK commercial sector are presented. These investigations have highlighted the reasons for non-adoption of SE practices and the problems which are currently restraining progress. Then, the actions are outlined which I believe must be undertaken for there to be a significant long term improvement. 


\section{PROBLEMS IN THE ADOPTION OF SOFTWARE ENGINEERING PRACTICES BY THE COMMERCIAL SECTOR WITHIN THE UK}

The SE practices which are likely to have the major impact on the quality of software for the commercial/administrative sector are those related to the use of:

- systematic development methods,

- computer based development support environments,

- quality assurance (QA).

Developments in each of these areas are primarily concerned with improvements in the software production process and should reduce the overall software wastage costs which have been estimated [2] for the UK as being in excess of 2,000 million pounds per year.

Evidence that SE practices were probably not being used sufficiently in the mid 1980s can be obtained from the detailed findings of a report produced in 1988 for the UK Department of Trade and Industry by consultants at Price Waterhouse [3] referred to above. However, a more recent picture of the state of the sector with regard to the use of systematic methods, CASE tools, QA approaches and standards can be obtained from work carried out by members of the Commercial SE group at the University of Sunderland. During the last six years members of the group have undertaken in depth investigations of practices within UK data processing departments via four major surveys and follow up case study interviews [4-9]. Within all these surveys the researchers had included questions assess the current state of the industry and assess the actual use of SE practices being investigated. There were also been questions to determine organisations' future plans, the constraints which are placed upon them and the problems that they encounter with regard to the area being surveyed. It is on these latter areas that I will concentrate in the remainder of this section.

\subsection{Current and Future Use}

Our surveys and related work have indicated that there is a continuing, if slow, increase in the use of methods, CASE and QA procedures. Certainly the situation would appear to have improved from that reported by the consultants from Price Waterhouse [3] but it is often difficult to estimate by how much. The continuing development of SSADM (Structured Systems Analysis and Design Method [10]) and its support from Government is leading to a greater acceptance of the value of the use of systematic methods. We are also sure that the situation regarding the use of CASE tools has improved since our 1990 survey. With regard to QA procedures the situation appears much more positive. Of the respondents to our 1991 survey $22 \%$ were already 3rd party assessed and almost half of these had only been certified within the last year, which was double the amount for the previous year. Positive figures for accreditation ( 24 businesses every three months) has also been reported in the UK Department of Trade and Industry's JFIT NEWS [11]. Nevertheless, given the size of the industry it is obvious that adoption of QA procedures across the whole of the UK software sector has still some way to go. We are sure that pressures from customers will cause a continuing adoption of QA procedures by the software industry but for QA to be really successful its adoption should be due to an internal desire for improvement rather than external forces. Nevertheless, overall what is very clear from our investigations is that there remains a significant proportion of the industry who have not adopted formal SE approaches and there is still a large percentage of software systems being developed without any QA procedures.

\subsection{Constraints and Problems}

One fundamental constraint on the adoption of SE practices is the lack of clear unbiased information. Another is simply human resistance to change. The major problems we have identified for each area and the common problems relating to human factors and are detailed in the following subsections:Methods. The major problems associated with the adoption of cost effective systematic development 
methods are:-

1. The current wide range of methods and techniques that are available and the lack of experienced staff and information/support. Plus techniques are often seen as too complicated and methods in many cases provide poor coverage of the lifecycle.

2. Unwillingness of organisations to accept change and adopt any new "standardised method". In many cases this is simply due to the costs, primarily in staff time, that are incurred with any major change. In other cases this is due to the fact that organisations have already invested heavily, and in some cases very heavily, in methods of their own.

CASE. The prospective market for CASE tools has been confused by the large variety of different products that are available. In an attempt to clarify matters tools have been categorised to more accurately describe their functions. Unfortunately, tool vendors and manufacturers have not fully agreed on what these terms mean, so such categorisation has simply added to the confusion, and not removed it. The other major problems are:

1. The current high cost of CASE tools. These costs were given as a major reason for not adopting CASE by the respondents to our The actual cost of CASE (per staff member) appeared to be approximately double what non-CASE users were willing to spend.

2. The high costs in terms of extra hardware and initial staff time in the adoption of CASE.

3. Lack of management support to invest in and use tools (and related methods).

Quality Assurance Procedures. Many organisations see no reason to seek accreditation to an external standard as they believe their own internal procedures are more effective. Other major reasons for not seeking an external standard have been identified as:

1. Cost of gaining accreditation and the time to implement new procedures.

2. General confusion over the meaning of quality when applied to software and a lack of knowledge of QA approaches and standards,

Human Problems. In the adoption of methods and tools there can be major problems with staff at all levels. People do not like change, especially if it is a possible threat to their livelihood or the way in which they have to work. Computing professionals are like everyone else in this respect. Managers lack confidence in their ability to understand and control the new technology whilst designers and production staff may believe that the methods and tools will destroy the artistic and creative aspects of their work. It is true that adoption of the new technologies has a large impact on working practices and that many members of staff have been unable (or are unwilling) to alter their working practices. We believe this "Luddite approach" has greatly contributed to the problems of implementing SE practices in the commercial/administrative sector.

Another human problem which we have identified during our work is that there is a deep seated antipathy to the use of standards throughout the industry. Most organisations and individuals formally recognise the value of standards and agree that they are needed. However, when it comes to the actual use of and adherence to standards the situation is in many cases very different [12]. This factor more than any other acts against any rapid increase in the acceptance of QA procedures since these more than any other SE practice depend on standards being adhered to.

\section{THE WAY AHEAD}

From our surveys and related investigations it has emerged that many of the reasons for the slow adoption of the approaches that should lead to the development of better quality software are related not to technology but to people. In fact I believe that to a great extent over the last 25 years we have concentrated too much on technological aspects and have failed to develop the human aspects that should be associated with any engineering discipline. The areas which I believe we now need to concentrate on, if we are to achieve quality in the future, are: professionalism, SE education within academic institutions, and technology transfer. 


\subsection{Professionalism}

It is absolutely essential that people at ALL levels, both within and outside the software industry, recognise that the production of quality software is as much an engineering discipline as any of the other traditional disciplines such as: mechanical engineering, electronic engineering, and civil engineering. It is vital that a high proportion of staff involved in software related projects are professionally qualified and that they place high regard on their professionalism with regard to ethics, responsibility and the attainment of quality. Traditionally when we attempt to measure quality during a software project we concentrate on metrics associated with the product (ie the code) and on the mechanics of how the product was developed. Little attention appears to be given to the quality of the staff involved in the process. This is despite the obvious fact that high quality staff are likely to produce a high quality product while poor quality staff are not. It would therefore seem that a simple project metric, such as the ratio of the number of professionally qualified staff involved on a project to the total number of staff, [13] is as likely to give a measure of the quality of the final product as established metrics such as that of Halstead [14].

\subsection{SE Education within Academic Institutions}

Academic institutions have been producing graduates and diplomates in computing-based disciplines in greater and greater number since the late 1970s. However, it would appear that despite all this new blood the "mind set" of the software industry appears not to be as positive towards SE practices and the production of quality products as it should be. Therefore, I must raise the question as to whether or not the students completing these courses are really equipped with the knowledge, skills and abilities which will enable them to immediately operate efficiently and effectively in the industry. Do their courses provide them with the necessary professionalism that should be expected? How do they compare in these areas with graduates in the more traditional engineering disciplines?

To achieve real improvement in the future, educational institutions need to take a much more pro-active role in promoting SE practices and professionalism. Also, this should not only be in named SE courses but in all computing courses from those closely related to business to those related to the more technological aspects of computing. It is also not sufficient to take a traditional computing topic such as algorithms and simply retitle it Software Engineering. There needs to be a change to an underlying approach which places a very high emphasis on aspects such as quality, professionalism, ethics and responsibility. It is important that these aspects need to be introduced at the start of any computing course and used throughout it. It is also important that emphasis is placed within these courses on interpersonal communications as SE practices have as much, if not more, to do with people than with machines. This aspect has been identified by the British Computer Society in its 1990 report on the Future of Information Technology [15] as the single most important skill required for effective participation in the IT society of the 1990s. As they stated "there is no computer substitute for clear thinking and accurate expression".

\subsection{Technology Transfer}

The achievement of quality in software can only be realised if the appropriate SE practices are implemented and used correctly. However, if the staff who are already in the industry are ill informed or fail to recognise the benefits of SE then any adoption is unlikely to be totally successful. It also must be recognised that, no matter how advanced the technology becomes, without good organisational attitudes it can do little to help surmount the many difficulties that currently face systems development staff. Also, for the correct practices to be adopted there is a clear need for accurate and meaningful information regarding their use. For new developments to be accepted within commercial/administrative organisations, there needs to be much better means of efficient and effective technology transfer.

For particular SE practices to be accepted and used there must be a much better understanding of 
them, their use and the actual benefits which they can bring. I must emphasise again that the underlying cause for several of the problems identified in the previous section is simply fear of the unknown coupled with a lack of unbiased, easily accessed information. To overcome such problems we need to create enabling mechanisms which will facilitate technology transfer and mutual understanding. In the UK the Institute of Electrical Engineers has already identified a number of such mechanisms [16] which it now intends to progress. However, it is not sufficient to simply produce the technology transfer material. It is imperative that there also is a will within the industry to receive such material with an open mind, appraise it in an impartial manner and where new practices are found to be appropriate, to adopt them willingly and with enthusiasm.

\section{REFERENCES}

1. Naur, P. and Randell, B. (Eds.), 1969, "Software Engineering: Report on a Conference Sponsored by the NATO Science Committee" (Garmisch, Germany October 7-11, 1968) published by Scientific Affairs Division, NATO, Brussels.

2. Dennis, M. 1991, TickIT: The DTI Involvement. Management and Design Division Colloquium on TickIT Certification Initiative: Objectives and Practice, IEE, London.

3. Price Waterhouse, 1988, "Software Quality Standards: The Costs and Benefits", Price Waterhouse Management Consultants, London, England.

4. Edwards, H.M., Thompson, J.B., and Smith P., 1989, "Results of a Survey of the Use of SSADM in Commercial and Government Sectors in UK", Information and Software Technology, Vol 31, No 1, 21-28.

5. Edwards, H.M., Thompson, J.B., and Smith P., 1989, " Experiences in the Use of SSADM: A Series of Case-Studies. Part 1: First Time Users.", Information and Software Technology, Vol 31, No 8, 411-419.

6. Edwards, H.M., Thompson, J.B., and Smith P., 1989, "Experiences in the Use of SSADM: A Series of Case-Studies. Part 2: Experienced Users.", Information and Software Technology, Vol 31, No 8, 420-428.

7. Stobart, S.C., Thompson, J.B., and Smith, P., 1991, "Use, problems, benefits and future direction of computer-aided software engineering in United Kingdom", Info. and Software Tech., Vol 33, No 9. 629-636.

8. Davis, C.J., Thompson, J.B., Smith, P., and Gillies, A.J., 1992, "A Survey of Approaches to Software Quality within the UK", Occasional Paper, No 92-5, School of Computing and Information Systems, University of Sunderland, UK.

9. Hardy, C., Thompson, J.B., and Edwards H.M., 1994, "A Preliminary Study of Method Use in the UK", Occasional Paper No 94-12, School of Computing and Information Systems, University of Sunderland.

10. CCTA, 1990 "SSADM Version 4 Reference Manual", NCC Blackwell, Manchester, England.

11. DTI, 1992, "TickIT programme: Launch of 1993 Awards", JFIT NEWS , No 39, DTI, Stevenage, UK.

12. Thompson, J.B., 1990, "A Software Tool and User's Reactions To It", Conference: Computer, Man and Organisation II, May, Nivelles, Belgium.

13. Thompson, J.B., 1993, Discussion following presentation of paper by Davis et al ("Current approaches to software quality assurance within the United Kingdom") at conference Software Quality Management, March, Southampton, England.

14. Halstead, M.H., 1977, "Elements of Software Science", North-Holland, Amsterdam, Holland.

15. BCS, 1990, "Future Impact Of Information Technology", British Computer Society, London, UK.

16. Kemp, A., 1993, "Software- where's the quality?" Computing and Control Engineering Journal, February, 45-47. 